\title{
On Care Robots and the Ethics of Tracking
}

A Transdisciplinary Ethics on Care Robots seen through a Posthuman and Performative Discussion on Tracking and Data Availability

This paper establishes a transdisciplinary exploration of care robots and their tracking capacity as an ethical performance. It does this to highlight the concerns around the ubiquity and availability of data in care contexts. In my attempt to scrutinise care robots beyond being humanoid and sociable actors, but instead as data tracking technologies, I link robot ethics, media and surveillance studies with posthuman and performative ethics to redefine tracking as an ethical microcosm within care robots. I do this, first, by challenging how to look at care robots and robot interactivity, particularly in reference to tracking as an ethical, not necessarily moral, question of interactivity and relationality. This angle will challenge the ethical timing and evaluation around tracking as an inherently ethical relation. Second, by arguing that the common ethical views on tracking are about concerns of privacy intrusion and data infringement while overlooking that a main ethical issue might not be a robotic intention to spy but the availability of data because of robots. Consequently, what deserves more attention in the ethics of robots is the growing ubiquity of care robots, the sensitivity of care contexts, and the acknowledgement of data appropriation; the latter being especially important considering the vulnerability of health care environments, and the growing commercial value of health data.

Keywords: Robot ethics, posthuman ethics, performative ethics, care robots, tracking, media and surveillance studies, health data, dataveillance

\section{Author Information}

Eugenia Stamboliev, University of Plymouth

eugenia.stamboliev@plymouth.ac.uk

ORCID: https://orcid.org/0000-0003-3839-1636

How to cite this article:

Stamboliev, Eugenia. "On Care Robots and the Ethics of Tracking - A Transdisciplinary Ethics on Care Robots seen through a Posthuman and Performative Discussion on Tracking and

Data Availability.” Információs Társadalom XX, no. 2 (2020): 101-117.

= https://dx.doi.org/10.22503/inftars.XX.2020.2.7

All materials

published in this journal are licenced

as CC-by-nc-nd 4.0 


\section{Introduction}

A transdisciplinary or transethical understanding of care robots, tracking and data as an entangled and ethical performance allows to rethink several aspects around care robots, which fall short in robot ethics. Tracking means multiple things in this paper. Technically, it refers to visual/haptic detection software and recognition systems or to tracking systems (Lin et al. 2012; Rossini 2012). Further, tracking can also refer to a strategic intention to survey and to collect data and information about customers, users, clients, or the elderly (Ball et al. 2012). Keeping this ambiguity on purpose will support me manoeuvring between these various dimensions throughout this paper as I position tracking as an ethical performance. The perspectives from posthuman and performative ethics used to expand on robot ethics will highlight the relationality of tracking and enable a critical discussion on care robots without having to focus on them as moral actors, or as un/suitable care takers, and without drifting into AI ethics. Instead, I will draw insights on thinking data concerns from media and surveillance studies to understand data availability differently. This will reposition the problem on tracking as surveillance from one on privacy intrusion towards one of data availability and robotic ubiquity. The difference being that I do contest the moment or approach when technology is considered ethical or morally charged in most ethical discussions by viewing tracking as inherently ethical.

The focus on tracking as a particular insight into the ethics of care robots is motivated by three different angles; to expand on robot ethics, to address the commodification of data and care, and to acknowledge the sensitivity of the care context. The first motivation lies in the necessity to blur the divide between anthropocentric and material discussions around robot technology to address the limits of moral evaluation in techno-economical innovation (Braidotti 2006; Donaghy 2001), which will offer new insights towards understanding robots holistically. The second angle on the robotisation of care links to; the ongoing digitalisation of health care, or 'Health 4.0' (Kickbusch 2019); the concerning growth of the commercial value of health data (Knoppers and Thorogold 2017); the commercialisation of care (Aulenbacher et al. 2018; Ford 2015); health technologies continuously converging with internet structures (Frank 2000); and the accelerated effort to position robots into elderly care, even if this is still at an experimental stage (Royakkers and van Est 2016; Lin et al. 2012). The third motivation to understand tracking better makes this discussion very specific, even if the angle on tracking and data seems transferable to other digital devices; the context of care is particularly ethically sensitive since it exposes vulnerable groups of people to an emerging data technology they might not understand fully, nor avoid exposure to. 


\section{On the ethical issues around care robots as companions or assistants}

In my attempt to scrutinise care robots ${ }^{1}$ not only as humanoid and sociable actors but as data tracking technologies, I bypass most discussions on why these devices are 'un/suitable' caretakers, or care assistants, and discourses dealing with the moral capacities, appearances, or actions of care robots (Royakkers and van Est 2016; Lin et al. 2012; Coeckelbergh 2009, 2010, 2018; Vandemeulebroucke et al. 2018; DeFalco 2017; Vallor 2011, 2016; Draper and Sorell 2017). Instead, I am establishing a transdisciplinary and transethical study on care robots to challenge what counts as ethical in robot ethics while focussing on posthuman and performative angles.

However, I would like to give a brief overview of the ethical discourses around anthropomorphism and care robots first. If viewed as humanoids, companions, or as assisting devices only, for the last twenty years robot ethics has dealt with various scenarios in which care robots or care technology assist, replace, or cooperate with human caretakers in care environments. ${ }^{2}$ Discussions around the ethics of the care robot are frequently occupied with their growing implementation in relation to the sensitivity of the people interacting with them (Turkle 2011; Wu et al. 2012; Krämer et al. 2011; Royakkers and van Est 2016; Lin et al. 2012; Sharkey and Sharkey 2010; Coeckelbergh 2009, 2015; van Wynsberghe 2012). Most ethicists in this field agree that if seen as a sociable companion (Krämer et al. 2011), robots should and will be treated as more-than-computers ultimately (Royakkers and van Est 2016). Therefore, their future acceptance as 'social actors' (Heerink 2011) is especially important in ethical terms considering that elderly care is a sensitive, communicative and trust seeking context in which the patients' dignity and safety is especially protection worthy (Sharkey and Sharkey 2010). ${ }^{3}$

On the one hand, anthropomorphic projections and intentions interrogate if and how robots will, or should be, positioned as assistants or replacements for human caretakers. Some argue that the implementation of care robots,

\footnotetext{
1 'Personal care and companions: Robots are increasingly used to care for the elderly and children, such as RI-MAN, PaPeRo, and CareBot. PALRO, QRIO, and other edutainment robots mentioned above can also provide companionship' (Lin et al. 2012, 944).

2 'According to the European Commission (2012), the proportion of those aged 65 years and over is projected to rise from $17 \%$ in 2010 to $30 \%$ in 2060, with the peak occurring around 2040. (...).' (Royakkers and van Est 2016, 62).

3 For now, care robots are mainly linked to anthropomorphic concerns (Duffy 2003). Media and surveillance studies (or cultural studies, feminist technology studies) does not deal with care robots as a technology since the field is rather interested in digital materiality or computational agency of the digital (Galloway 2012; Andrejevic 2012), while the socio-economic canons, which look at care, would rather look at the marketisation of care as ethically problematic and to robots as instrumental in this process (Ford 2015; Green and Lawson 2011).
} 
especially as companions, could be an isolating process for the elderly (van Wynsberghe 2012); could objectify the elderly (Sharkey and Sharkey 2010); or that it could be understood as deceptive on the grounds of robots affording, but not exhibiting, emotions or care (Sharkey and Sharkey 2011; Turkle 2011). Another ethical critique lies in the very principle of anthropomorphism, as social robots are meant to push our 'Darwinian buttons' (Scheutz 2012, 215) under a 'false pretence', which can 'automatically trigger inferences about other agents' mental states, beliefs, desires, and intentions' (216). ${ }^{4}$

On the other hand, techno-philosophers, like Floridi (2014), consider any form of 'anthropocentric agenthood' (187) misleading by mistaking the robot for an entity. For him, data issues around robots must be detached from the perception or thinking of robots as human-like entities, which represents wider approaches of AI or data ethics towards robots. Dumouchel \& Damiano (2017), or Coeckelbergh (2010, 2018), suggest another approach towards relational thinking of social robots that also questions the agenthood stability initially drawn from Cartesian modelling of robots (and humans). While both angles have moved beyond ontological thinking, relational (moral) 'patiency' theories (Gunkel 2012; Coeckelbergh 2018) still emphasise the social and embodied element of technology without declaring the robot as instrumental, or as a data machine only.

\section{From monitoring to an ethical and performative view on tracking}

While my concerns are not specifically linked to how robots are perceived, I do not transfer this discussion into AI ethics or to research on algorithmic morality (Floridi and Taddeo 2016), nor do I suggest ignoring discussions on robots as moral artefacts (Kroes and Verbeek 2014). As I leave the previous discussions on anthropomorphism without dismissing their concerns, my research is mainly concerned with expanding these through new ethical and disciplinary angles (Stamboliev 2019). Despite my ethical position advocating for posthuman and performative perspectives to join, the discussion I am about to establish is not being fully transformed into a posthuman nor processual one. The main reason is that neither posthumanists nor performative approaches are necessarily concerned with looking at one particular technological body or implementation, let alone at care robots, and this would leave no space to address the sensitivity of care contexts. However, both posthuman thinking and performative approaches have arrived in philosophy of technology (Coeckelbergh 2019) as well as in

\footnotetext{
4 Anthropomorphism does not have to be understood as deceptive mistake (Duffy 2003), but is a helpful predisposition to increase the acceptance of robots, especially within environments such as elderly care, where the resistance towards bulky and scary devices could be significant (Wu et al. 2012).
} 
science and technology studies (STS) (Licoppe 2010) challenging ontological stabilities increasingly, but rarely the focus on moral philosophy.

Next, I will scrutinise the existing view on tracking in robot ethics to then suggest a performative perspective on tracking, which then ultimately shifts to a media-material view on data leading to the concerning part of this paper; dataveillance and elderly care.

The various angles I propose will contest how we understand data issues around care robots and when these emerge. The focus on the timing of the ethical discussion is crucial. What I mean by timing can also be understood as the difference between evaluative ethics and structural ethics. I argue that an ethical understanding of technology does not have to be only evaluative or problem-based, but can view robots as inherently ethical structures, which is an apriori discourse opposed to the projections and concerns often raised in robot ethics. The latter focuses - like most moral philosophy - on specific moments, issues, errors, or on virtues. The ethical issues, which keep reappearing in robot ethics, focus on deception, isolation, and a lack of emotionality (see I.), or as explained next, on tracking as spying. These are evaluative concerns that often guide the ethical discussions by raising questions on virtues and abilities - or the lack thereof. ${ }^{5}$ The difference being that posthuman ethics views technology as inherently ethical describing and contesting its relation and structure to subject formation, environment, and capitalism (Braidotti 2006).

\section{On the difference between tracking-as-spying and tracking-as-ethics}

Tracking has not gone unnoticed as a concern. Mainly because it is often linked to surveillance technology and viewed critically by media and surveillance scholars. Researchers from information and technology studies, like Nissenbaum (2010), refer to monitoring and tracking simultaneously as the ability 'to watch over people, to capture information about them, and to follow them through time and space' (10), while in computing and web design, tracking also has negative connotations and is linked to the instalment of cookies and strategic surveillance (Acar et al. 2014).

Tracking is a concern for robot ethics as well, but less so when it comes to care robots, since these usually drop out from the narrative of being a potential spying technology (see I.). Still, in some care robot discussions, tracking is mentioned as aligned with monitoring and privacy intrusion and often used synonymously. While I understand why this is a valid concern, I do not fully agree with the belatedness and evaluation of this process and its alignment

\footnotetext{
5 The motivation behind any posthuman thinking is critical towards moral philosophy or philosophy of technology. Often, posthuman approaches challenge standardised and universalized debates on subjectivation, technology, morality and expose capitalist interests in the making of emerging technologies (Braidotti 2006).
} 
to immoral monitoring (Stamboliev 2019). For instance, two prominent robot ethicists, Sharkey and Sharkey (2010) state that:

'Robotic surveillance devices have already been developed for warfare, for policing and for home security (Sharkey 2009) and these could easily be adapted for monitoring the elderly. A robot that traverses the house, and relays information picked up by its sensors, is something that is well within the current technological limits' (2010, 32).

For them, monitoring is problematic (while having positive aspects too), because it enables unconsented spying on the elderly (I assume they mean by the caretakers?). This would intrude upon people's privacy, which is a worrisome possibility. While they also highlight that it is not clear who has access to the data robots gather or its management ${ }^{6}$, they do not fully unpack the scale of this data problem. Hence, my intervention comes in at this point: I state that even if robot ethics is (rightfully) concerned, most views on tracking are somewhat limited.

For instance, tracking is always moralised when mentioned, even if it is not per se moral in its technical intentionality. Still, it is not a neutral process, while it is not simply spying either. It might be intentional, but it is not conscious. There is no ethical (relational) debate on its becoming, while I argue there should be, because tracking negotiates between human values and input, and technological capacities and output. Further, there seems to be a lack of acknowledgment that the ethical issues around digital tracking technology are intimately embedded in social robots being interactive data devices. If one wants robots to be interactive technologies, tracking is a minimum technical requirement, and the handling of data is part of this process. This does not have to be per se problematic, and yet it is. Hence, the challenge in redefining tracking will be about how to think the potential of data and not the intention to spy; each exhibiting a different approach to when technology becomes ethical.

To understand this better, I need to explain how tracking functions. The technical side of tracking refers to recognition/detection modules or systems, which are mostly researched in the field of Human-Robot-Interaction (HRI) or in computer studies. Just like any interactive technology, care robots must exhibit a certain level of aliveness and responsiveness to be placed into human contexts and to not be perceived as uncanny (Mori 2012; Ravetto-Biagioli 2016). Yet, tracking is extremely difficult to perform - ethically and technically

6 '(...) forget that the robot was monitoring them, and could perform acts or say things thinking that they are in the privacy of their own home. Moreover, who should have access to the information, and how long it should be kept for? With the massive memory hard drives available today, it would be possible to record the entire remainder of an elderly person's life, but this is not something that they would necessarily consent to if they were able to' (Sharkey and Sharkey 2010, 32). 
speaking. What is even harder, is its synchronisation to locomotion and movement (Brèthes et al. 2004; Rossini 2012). Why is this the case? Tracking systems require a certain sophistication building on 'advancing biometrics capabilities and sensors, and database integrations' (Lin et al. 2012, 946), which enables synchronisation of input with output (and best case, with locomotion). First, the robot's tracking module requires clear instructions and accurate concepts of what to detect (human, gesture, emotion). ${ }^{7}$ Second, these steps rely heavily on the computational capacities of the robot to be (operationally) autonomous and able to process information in real-time; otherwise, no interaction with a human, no HRI, can be established (Tseng et al. 2016).

\section{Tracking as a performative and ethical relation}

Advocating for an ethical perspective on tracking (not a moralistic one) means to focus on the relationship between computational capacities of robots as interactive data machines, and on the programmer's input or commands as being entangled, not viewing them as distinct entities. Since tracking requires data input and processing capacity to allow for the robot to interact, the robot and data are always entangled in their becoming. Hence, tracking acts as a microcosm that demonstrates why an ethical discussion on robots does not begin with the privacy intrusion or monitoring, and why it could even be seen as a form of posthuman caring emphasising the relationality embedded in its performance. Thinking the robot's capacity to track human movement as a form of posthuman caring could even allow for the human and non-human interaction to be understood as a (visual) computational feedback loop, which should not be understood as a romanticised thought about the robot becoming emotional. The reinterpretation of caring as tracking, and tracking as caring, only makes it easier to consider technological interactivity as a fluid performance of attention, recognition, and responsiveness.

Further, tracking could also be viewed as performing ethics through robots, less through attributing moral codes to technological capacities, neither as a linear nor a neutral chain of commands, but as very relationality between human and robot. Barad's take on performativity (2003) is helpful in this thought experiment since not only can tracking be a form of caring, but the fluidity and processuality questions the human and non-human borders inherently. Barad (2003) proposes 'a posthumanist notion of performativity-one that incorporates important material and discursive, social and

\footnotetext{
7 One underlying program embedded into a tracking module, is, for instance, Ekman's Facial Action Coding Scheme, FACS. The FACS is still a highly popular psychological scheme on emotional expressivity designed by Ekman in the 1970s. It suits the detection of 'basic' emotional states in human faces. It is also heavily critiqued by now for being reductionist, and also culturally and racially biased. See Knapp and Hall (2014) and Gates (2011).
} 
scientific, human and nonhuman, and natural and cultural factors' (809). She relates this to the work of Butler on performativity, and on the materialisation and becoming of gender. Without fully making this a processual discussion, I place the attention on the dynamics of the 'ongoing reconfiguration of the world', not as distinct entities, causalities or attributes (818)' (Barad 2003). This view is linked to thinking data as ethical, therefore, every level in the robot (aka in every technology) can be discussed in this manner, and most importantly, nothing is ever non-ethical. To some extent, this view relates to early machine morality research. Wallach and Allen (2009) were two of the early scholars to point out that the engineer's intention and values influence computational decision making to a high degree.

Avoiding an ontological causality between engineer and machine, the performative and posthuman thinking (which is interrelated, but not identical) refuses to deal with entities or ontologies of the human and the robot (among other things) - and specifically refuses any moral universality (Braidotti 2006). Instead, an ethical view on tracking as an ethical and performative entanglement of human concepts and technological capacities does lead to new 'ethical complexities' (Braidotti 2006: 16) that further do 'not intend to provide guidelines for a practical morality' (Luhmann 1989: 112). This amplifies the fluidity and continuity between human and non-human agencies coming together in the becoming of matter and meaning of technology as ethics. This also enables redefining the boundaries between intention and possibility, between predicting and moralising potential future interferences and errors from the human-centred perspective; or studying the capacities and networks from a technology-centred perspective.

Ultimately, what the discussion on the performativity of tracking magnified is the relationality and fluidity between human and posthuman intentions, as potentials and interactions within the becoming of technology, which I define as ethical. The reason why this discussion is not aligned to AI ethics or data ethics is the posthuman and performative element that expands the ethical without deepening a discussion on morality. Yet, the issues with tracking are not unknown in robot ethics (neither in AI ethics). The difference in my approach is that I understand tracking as an inherently ethical relationship between robot and human, and not as a question or process of privacy intrusion through im/morally guided robots. The inherently ethical potential of tracking, however, shows more; it points out that the robot's interactivity is dependent on an interplay of data throughout.

From this, a new concern arises; tracking generates data, even without carrying an intention to spy on anyone. To explain the ethical potential of tracking generating data, I will situate the discussion back to the care robot as technology in elderly care. From understanding tracking ethically, I move towards explaining why the care robot's implementation into care runs the risk of becoming a different form of surveillance, nonetheless. 


\section{On the ubiquity of care robots, data availability, and the sensi- tivity of elderly care}

Tracking being ethical and performative is one thing, tracking enabling $d a$ taveillance $^{8}$ is another. The latter implies an actual ethical (sometimes legal) issue enabled through tracking systems, which is not as such one about an immoral spying through/of robots or their developers, but is one about making data even more available through ubiquitous technology.

As I define it, tracking can become problematic in two ways, which are both still grounded in the previous discussion. First, creating and programming tracking modules is an inherently ethical performance charged with future information. According to Gitelman (2013), such information is embedded in the potential of data. ${ }^{9}$ Hence, one must understand that the availability of data already carries a concerning and ethical potential prior to the actual misuse of data through immoral robots, or them spying. Now, someone could argue, this still adds a disguised moral judgment to the debate. Yet, I insist on this not being the case since this viewpoint does not identify any specific wrongdoing, or evaluative judgement in this process. ${ }^{10}$ When data becomes available, it will very likely be appropriated. This is its structural potential. Still, this gets problematic, if this very potential is not taken seriously and understood fully. Therefore, second, by expanding on the use of social robots into care as a sensitive context, we do increase the potential for the previous possibilities to become an actual ethical issue.

Andrejevic (2012) argues, from a media and surveillance studies perspective, that one essential change in the logic of surveillance in our era of automated data collection and processing is that such has moved away from traditional surveillance. For him, surveillance does not require any subject's (nor robot's) internalisation of a monitoring gaze while he is particularly alert to the ubiquity of information technology accelerating the 'ubiquitous' structure of technology towards a 'ubiquitous surveillance' (91) - by default, not by intention.

8 Clarke (1988) defined it as a 'systematic use of personal data systems in the monitoring or investigation of the actions or communications of one or more persons' (499).

9 I do not draw a clear distinction between data and tracking, whereby, I consider tracking in the centre of this discussion. However, even data can be viewed as ethically charged. Galloway (2012) argues that data has a 'phenomenological claim' (82), but it is not yet information. Gitelman (2013) highlights that data already carries the potential of future information. Gitelman most resonant statement is that there is no raw data $(2013,1)$, which becomes a crucial tenet for critical data studies (Richterich 2018). She warns that our lack of criticality allows us to ignore the fact that data is always designed, stored, collected, gathered, etc. Hence, at 'a certain level the collection and management of data may be said to presuppose interpretation' (3).

10 My concerns focus on a lacking technical transparency rather than on a lack of good or conscious robots as I do not expect any moral judgment from robots. However, I do not advocate for an amoral discussion about robots at any point, but in this paper, establishing new techno-ethical dimensions seem more fruitful and closer to my background as a media philosopher. 
As the pervasion of communication technologies has further broadened the spatial infiltrations, care environments might not be exempt from these developments. Increasingly more environments are regulated under the umbrella of 'networked interactivity' (92) allowing for the technologies to 'recognize us wherever we go, responding to our presence in ways that incorporate information about our histories, desires, needs, and wants' (92).

Ball et al. (2012) emphasise these changes being a refiguration from the traditional 'strategic surveillance' towards one that is a distributed, non-strategic information structure (Ball et al. 2012, xxv). This 'new form' of spying has become a by-product of simply applying a digital and data gathering technology in new contexts. Gathering more data would lead to more data being appropriated. Enhanced by this very robotic ubiquity, we run the risk of creating more dataveillance ${ }^{11}$ through structures already put in place (and simultaneously expanded upon). This, theoretically, less strategic spying is referred to as an 'algorithmic surveillance' (Introna and Wood 2002), because it is structurally entangled with the algorithmic and computational level from which it feeds. What scholars, like Andrejevic or Ball, clearly present is that an intention to spy is not required (but still possible) as data collecting has merged with communication and digital structures. We face a new paradigm towards spying as enabled by the promise of a comprehensive data collection. This allows prediction and pre-emption to replace deterrence (Andrejevic 2019).

This angle has supported my argument about the ethical timing as I argued that privacy intrusion might be a belated concern in robot ethics since such only emerges when intrusion or misuse is to be avoided, while not asking if the care robot is in principle a problematic device by implementation and capacity. However, there is already research that pays much more attention to the importance of design and ethics. For instance, van Wynsberghe (2012) developed her approach towards Care Centered Value Sensitive Design (CCVSD) to rethink the role of design into the ethical sphere, but also to interrupt what calls the 'vicious circle'; an unchallenged dominance of industry in the implementation of robots. Others focus on integrating ethical design approaches (Dodig Crnkovic and Cürüklü 2012) also having in mind the improvement of robot virtues (Vallor 2018) whereby the ethical dimension of tracking or data prior to the concern of data misuse or infringement, is often neglected.

Eventually, the expansion of automated and ubiquitous data structures (devices) the possibility of endless data appropriation, definitely multiplies the concerns around care robots. Especially, as more digital technologies are merging with medical health services (Knopper and Thorogood, 2017), it is worrisome when Schermer (2007) states that 'surveillance practice will become more efficient, more user friendly, and more complete through the use

11 The term dataveillance is rarely used today, since mostly referred to as Big Data, but to emphasise the shift from surveillance to data-veillance, I have stuck to this term on purpose. 
of agent technology' (133). While I still question the possibility of strategic surveillance of care patients, or in health environments, becoming legal or socially accepted, I strongly anticipate growing commercial interest in the data circulating in these contexts.

\subsection{The practical side of robots, tracking, data concerns, and elderly care}

Is the potential danger of robots in elderly care to be data-mongering surveillance technologies just a far stretched and fatalistic outlook from a media philosopher? Let me contextualise my previously raised critique within the practical tendencies found in present robotics research. I will present two problematic application issues around social/care robots, which demonstrate the existing developments for my concerns. First, I will address the issue that care (social) robots are easily hackable, and second, I will point to their application being fused with Big Data analytics.

First, the social robot Pepper (a prominent research/social robot applied for elderly or health care in Japan) has already faced system breaches and was labelled as an 'insecure' and easy-to-hack technology (Chirgwin, 2018). In 2018, Giaretta and colleagues tested the data security barriers of humanoids like Pepper and NAO and discovered that these devices are extremely easy to hack; accessing their servers was easily achieved. Resulting from this, it can be argued that it is much likelier that we are about to implement hackable and data-sensitive robots into elderly care than friendly humanoid companions. The argument in the study differs from mine in this paper since the researchers deal with the already mentioned moment of ethical error or conflict, which means they assume that the data is initially neutral prior to being hacked, which I presented as a belated ethical concern. However, independent of the ethical approach, what they find equally alarming is the lack of urgency around data security in social robots. Sylvia's (2016) view on how privacy protection is approached in this field, is much more direct by arguing that discussions on data protections are presented as red herring debates that mask 'a much larger argument about the changing character of the risks stemming from the power differential created by corporate control of information' (20).

Second, there is a more explicit linkage to the critical point I made about dataveillance, which proves that service (or care) robots are attached to Big Data software and to elderly care already. Under the assumption that humanoid service robots are becoming an increasingly big part of our daily lives, Jiang and Zhang (2015) suggest to synchronise these with Big Data Analytics software 'equipped with distributed and scalable data processing and intelligent analysis ability' (144) as a 'flexible and efficient method to support incremental data collection, storage and knowledge model', which allows to enhance robot-robot communication but also 'distributed collaboration' (144). If understood correctly, this means plainly; data is collaboratively exchanged 
between robots, fetched from contexts such as elderly care or educational contexts, which they specifically refer to, and moved and stored on various clouds and online storages while access and ownership remain open points. This research does not raise any ethical flags for the authors, but is described as technically complex, which it surely is.

While the research of Jiang and Zhang shows that aiming for synchronisation of Big Data Analytics to emotion and gesture tracking in elderly care, or in education, is a technological challenge and not an ethical one, I strongly urge not to distinguish between these two. Especially, when we consider the sensitivity of data and the vulnerability of people exposed to robots, the technological advancements must develop in parallel with an ethical understanding thereof. In the end, we are debating the rights and dignity of people who despite not being a homogenous group at all, will be potentially exposed to unknown devices in moments of pain, helplessness, confusion, or inability to consent or understand. Gaining or managing the data from vulnerable groups is an inherently problematic process, and if we include the sociably acceptable companion position of robots, even more so. These devices might become more than mere entertainment but might gain in status and importance in some people's lives. The tracking capacity of care robots cannot be regarded as the same concern as this would be for computers, or on digital platforms, given that the latter are part of people's lives by choice, while no one's life depends on their usage. This might be a very different scenario considering the future dependency on care robots or care technology.

\section{Conclusion}

The care robot is a very particular technology considering what relationship it will afford. Maybe we will accept it as a humanoid and social actor, but surely, it will function as a data gathering device. As an example of technological innovation affecting a vulnerable group of people, the care robot enabled a transdisciplinary review on how technologies are always social, ethical and consequential. Instead of asking if care robots are deceptive or isolating companions for vulnerable humans and focusing on their appearance only, I argued that robots are more than un/suited caregivers; they are already good enough data tracking machines. What I emphasised was to look at tracking as a performative and ethical performance related to design, data collection, and implementation of care robots. As such, I came to suggest that it is not sufficient to address the concern of privacy intrusion as a potential ethical issue in robot ethics, and in addition, that we should change our perspective on data. The reason being that data changes in its functionality and can be appropriated, and commercialised after being gathered.

Linking robot ethics; media and surveillance studies; and posthuman and performative ethics, not only enabled an understanding of tracking as an 
ethical microcosm within care robots, but it pointed to the ethical and performative dimension of tracking, and the sensitivity of data and elderly care. Focussing on tracking as an inherently ethical process led to questioning if privacy intrusion and data infringements could be a belated concern of robot ethics pointing to a difference in ethical timing. The new ethical perspective I suggested shifted the focus from data infringement towards data availability, and opened a discussion on ubiquity as it positioned care robots as potential dataveillance.

Still, it is not that AI or robot ethics has not raised similar concerns about the sensitivity of health care environment, or on data fetched from robots. Yet, my approach was meant to change the discussion through altering the ethical approach, and timing, and through creating a transdisciplinary engagement that left robot research and moral philosophy aside at points. Even though the linkage between surveillance and care robots could evoke some resistance from ethicists or roboticists defending a purely utilitarian motif towards improving care technology, I pointed out that the hackability of social robots and their tracking capacities being fused with Big Data software raises underestimated and unnoticed ethical red flags. If what van Dijck (2017) proclaims as the 'normalization of datafication as a new paradigm in science and society' (39) aligns with the increased 'mediatisation' of social structures (Hepp and Krotz 2014), care contexts might face various data and infringement issues, which might be easier to identify by looking at ethical schools that do already place critical, yet not technophobe, angles on emerging digital technologies as being problematic data gathering technologies. Ultimately, the ongoing transformations of professional care and labour conditions; the implementation of digital data machines; the commodification of care and robots; the vulnerability of patients or clients; and the value of their data - each topic demands a much broader and transdisciplinary attention beyond picking techno-philosophical traditions without neglecting disciplinary expertise and foci, but by encouraging new synergies and linkages to understand techno-ethical concerns even better.

\section{References}

Acar, Gunes, Christian Eubank, Steven Englehardt, Marc Juarez, Arvind Narayanan, and Claudia Diaz. "The Web Never Forgets." Proceedings of the 2014 ACM SIGSAC Conference on Computer and Communications Security-CCS '14, 2014.

https://doi.org/10.1145/2660267.2660347.

Andrejevic, Mark. "Ubiquitous Surveillance.” In Routledge Handbook of Surveillance Studies, edited by Kristie Ball, Kevin Haggerty, and David Lyon, 91-98. New York: Routledge, 2012. 
Andrejevic, Mark, and Mark Burdon. "Defining the Sensor Society.” Television \& New Media 16, no. 1 (July 11, 2014): 19-36. https://doi.org/10.1177/1527476414541552.

Aulenbacher, Brigitte, Fabienne Décieux, and Birgit Riegraf. “Capitalism Goes Care.” Equality, Diversity and Inclusion: An International Journal 37, no. 4 (May 21, 2018): 347-60. https:/l doi.org/10.1108/edi-10-2017-0218.

Ball, Kristie, Kevin D. Haggerty, and David Lyon. Routledge Handbook of Surveillance Studies. New York: Routledge, 2012.

Barad, Karen. "Posthumanist Performativity: Toward an Understanding of How Matter Comes to Matter.” Signs: Journal of Women in Culture and Society 28, no. 3 (March 2003): 801-31. https://doi.org/10.1086/345321.

Braidotti, Rosi. “Transpositions on Nomadic Ethics”. Cambridge Polity Press, 2006.

Brèthes, Ludovic, Paulo Menezes, F. Lerasle, and Jean-Bernard Hayet. "Face Tracking and Hand Gesture Recognition for Human-Robot Interaction.” Proceedings of the 2004 IEEE InternatIonal Conference on Robotic Automation, 2004, 1901-6. https://doi.org/10.1109/ROBOT.2004.1308101.

Chirgwin, Richard. “Softbank's 'Pepper' Robot Is a Security Joke.” www.theregister.co.uk, May 2018, 29AD. http://www.theregister.co.uk/2018/05/29/softbank pepper_robot multiple basic_security_flaws/.

Clarke, Roger. "Information Technology and Dataveillance." Communications of the ACM 31, no. 5 (May 1, 1988): 498-512. https://doi.org/10.1145/42411.42413.

Coeckelbergh, Mark. "Care Robots and the Future of ICT-Mediated Elderly Care: A Response to Doom Scenarios.” AI \& SOCIETY 31, no. 4 (October 28, 2015): 455-62. https://doi.org/10.1007/ s00146-015-0626-3.

Coeckelbergh, Mark. "Health Care, Capabilities, and AI Assistive Technologies.” Ethical Theory and Moral Practice 13, no. 2 (July 17, 2009): 181-90. https://doi.org/10.1007/s10677-0099186-2.

Coeckelbergh, Mark. "Moral Appearances: Emotions, Robots, and Human Morality.” Ethics and Information Technology 12, no. 3 (March 17, 2010): 235-41. https://doi.org/10.1007/ s10676-010-9221-y.

Coeckelbergh, Mark. "Moved by Machines: Performance Metaphors and Philosophy of Technology.” New York: Routledge, 2019.

Coeckelbergh, Mark. "Why Care About Robots? Empathy, Moral Standing, and the Language of Suffering.” Kairos. Journal of Philosophy \& Science 20, no. 1 (June 1, 2018): 141-58. https://doi.org/10.2478/kjps-2018-0007.

Davisson, Amber, and Paul Booth. Controversies in Digital Ethics. New York: Bloomsbury Academic, 2016.

DeFalco, Amelia. "Beyond Prosthetic Memory: Posthumanism, Embodiment, and Caregiving Robots.” Age, Culture, Humanities: An Interdisciplinary Journal 2016, no. 3 (2017): 1-34. http://eprints.whiterose.ac.uk/105361/.

Dodig Crnkovic, Gordana, and Baran Çürüklü. "Robots: Ethical by Design.” Ethics and Information Technology 14, no. 1 (August 24, 2011): 61-71. https://doi.org/10.1007/s10676-011-9278-2.

Donaghy, Kieran. "Some Moral, Ethical, and Transethical Issues Raised by Biotechnology and How We Might Deliberate About Them.” American Behavioral Scientist 44, no. 8 (April 2001): 1267-82. https://doi.org/10.1177/00027640121956818. 
Draper, Heather, and Tom Sorell. "Ethical Values and Social Care Robots for Older People: An International Qualitative Study.” Ethics and Information Technology 19, no. 1 (December 8, 2016): 49-68. https://doi.org/10.1007/s10676-016-9413-1.

Duffy, Brian R. “Anthropomorphism and the Social Robot.” Robotics and Autonomous Systems 42, no. 3-4 (March 2003): 177-90. https://doi.org/10.1016/s0921-8890(02)00374-3.

Dumouchel, Paul, and Luisa Damiano. "Living with Robots.” Cambridge, Mass.: Harvard University Press, 2017.

Floridi, Luciano. "Artificial Agents and Their Moral Nature.” In The Moral Status of Technical Artefacts, edited by Peter Kroes and Peter-Paul Verbeek, 185-213. Dordrecht: Springer Science+Business Media, 2014.

Floridi, Luciano, and Mariarosaria Taddeo. "What Is Data Ethics?” Philosophical Transactions of the Royal Society A: Mathematical, Physical and Engineering Sciences 374, no. 2083 (December 28, 2016): 20160360. https://doi.org/10.1098/rsta.2016.0360.

Ford, Martin. "Rise of the Robots: Technology and the Threat of a Jobless Future." New York: Basic Books, 2015.

Frank, Seth R. "Digital Health Care-The Convergence of Health Care and the Internet." Journal of Ambulatory Care Management 23, no. 2 (April 2000): 8-17. https://doi.org/10.1097/00004479-200004000-00003.

Galloway, Alexander R. “The Interface Effect.” Cambridge, Uk ; Malden, Ma: Polity, 2012.

Gates, Kelly. "Our Biometric Future : Facial Recognition Technology and the Culture of Surveillance.” New York: New York University Press, 2011.

Giaretta, Alberto, Michele De Donno, and Nicola Dragoni. “Adding Salt to Pepper.” Proceedings of the 13th International Conference on Availability, Reliability and Security - ARES 2018, 2018. https://doi.org/10.1145/3230833.3232807.

Gitelman, Lisa. “Raw Data” Is an Oxymoron.” Cambridge: MIT Press, 2013.

Green, Maia, and Victoria Lawson. "Recentring Care: Interrogating the Commodification of Care.” Social \& Cultural Geography 12, no. 6 (September 2011): 639-54. https://doi.org/10.1 $\underline{080 / 14649365.2011 .601262 .}$.

Gunkel, David J. Machine Question - Critical Perspectives on Ai, Robots, and Ethics. MIT Press, 2012.

Heerink, Marcel. "How Elderly Users of a Socially Interactive Robot Experience Adaptiveness, Adaptability and User Control.” In 12th IEEE International Symposium on Computational Intelligence and Informatics, 79-84. IEEE, 2011.

Hepp, Andreas, and Friedrich Krotz. "Mediatized Worlds : Culture and Society in a Media Age. “ Basingstoke, Hampshire: Palgrave Macmillan, 2014.

Introna, Lucas, and David Wood. "Picturing Algorithmic Surveillance: The Politics of Facial Recognition Systems.” Surveillance \& Society 2, no. 2/3 (September 1, 2002). https://doi. org/10.24908/ss.v2i2/3.3373.

Jiang, Ming, and Li Zhang. "Big Data Analytics as a Service for Affective Humanoid Service Robots.” Procedia Computer Science 53 (2015): 141-48. https://doi.org/10.1016/j. procs.2015.07.288.

Kammerer, Dietmar, and Thomas Waitz. “ÜBERWACHUNG UND KONTROLLE.” Zeitschrift Für Medienwissenschaften 13, no. 2 (2015). https://www.zfmedienwissenschaft.de/heft/archiv/ ausgabe-13-ueberwachung-kontrolle. 
Kickbusch, Ilona. "Health Promotion 4.0 (Editorial)." Health Promotion International 2019, no. 34 (2019): 179-81. https://doi.org/10.1093/heapro/daz022.

Knapp, Mark L, and Judith Hall. "Nonverbal Communication in Human Interaction.” Southbank, Victoria: Thomson Wadsworth, 2014.

Knoppers, Bartha Maria, and Adrian Mark Thorogood. "Ethics and Big Data in Health.” Current Opinion in Systems Biology 2017, no. 4 (2017): 53-57.

Krämer, Nicole C., Sabrina Eimler, Astrid von der Pütten, and Sabine Payr. “THEORY OF COMPANIONS: WHAT CAN THEORETICAL MODELS CONTRIBUTE TO APPLICATIONS AND UNDERSTANDING OF HUMAN-ROBOT INTERACTION?” Applied Artificial Intelligence 25, no. 6 (July 2011): 474-502. https://doi.org/10.1080/08839514.2011.587153.

Kroes, Peter A, and Peter-Paul Verbeek. “The Moral Status of Technical Artefacts.” Dordrecht; New York Springer, 2014.

Lin, Patrick, Keith Abney, and George A Bekey. "Robot Ethics: The Ethical and Social Implications of Robotics.” Cambridge, Mass.: Mit Press, 2012.

Mori, M. The Uncanny Valley. In IEEE Robotics \& Automation 12 (2012): 98-100.

Nissenbaum, Helen Fay. "Privacy in Context: Technology, Policy, and the Integrity of Social Life." Stanford: Stanford Law Books, 2010.

Ravetto-Biagioli, Kriss. “The Digital Uncanny and Ghost Effects.” Screen 57, no. 1 (March 2016): 1-20. https://doi.org/10.1093/screen/hjw002.

Richterich, Annika. “The Big Data Agenda: Data Ethics and Critical Data Studies.” London: University Of Westminster Press, 2018.

Rossini, Nicla. "Reinterpreting Gesture as Language: Language in Action.” Amsterdam: IOS Press, 2012.

Royakkers, Lambèr, and Rinie Van Est. "Just Ordinary Robots. Automation from Love to War." London: CRC Press, 2016.

Schermer, Bart. "Software Agents, Surveillance, and the Right to Privacy: A Legislative Framework for Agent-Enabled Surveillance.” Thesis, 2007.

Scheutz, Matthias. "The Inherent Dangers of Unidirectional Emotional Bonds between Humans and Social Robots.” In Robot Ethics: The Ethical and Social Implications of Robotics, edited by Patrick Lin, Keith Abney, and George Bekey, 205-22. Cambridge, Mass.: MIT Press, 2012.

Stamboliev, Eugenia. "Challenging Robot Morality: An Ethical Debate on Humanoid Companions, Dataveillance, and Algorithms.” Thesis, University of Plymouth, 2019.

Sylvia, J. J. "Little Brother: How Big Data Necessitates an Ethical Shift from Privacy to Power." In Controversies in Digital Ethics, edited by Amber Davisson and Paul Booth, 13-29. New York: Bloomsbury Academic, 2016.

Tseng, Shih-Huan, Yen Chao, Ching Lin, and Li-Chen Fu. "Service Robots: System Design for Tracking People through Data Fusion and Initiating Interaction with the Human Group by Inferring Social Situations.” Robotics and Autonomous Systems 83 (September 2016): 188-202. https://doi.org/10.1016/j.robot.2016.05.004.

Turkle, Sherry, and Basic Books. "Alone Together: Why We Expect More Form Technology and Less from Each Other.” New York: Basic Books, A Member Of The Perseus Books Group, 2011.

Vallor, Shannon. "Carebots and Caregivers: Sustaining the Ethical Ideal of Care in the Twenty-First Century.” Philosophy \& Technology 24, no. 3 (March 31, 2011): 251-68. https://doi. org/10.1007/s13347-011-0015-x. 
Vallor, Shannon. "Technology and the Virtues a Philosophical Guide to a Future Worth Wanting.” New York, Ny, United States Of America Oxford University Press, 2016.

Vandemeulebroucke, Tijs, and Chris Gastmans. "The Ethics of Care Robots in Aged Care: An Overview of Ethical Argumentations and Concepts,” 2017. http://www.academyforlife.va/ content/dam/pav/documenti\%20pdf/2019/Assemblea2019/TestiRelatoriPubblicati/FT\%20 Gastmans.pdf.

Wallach, Wendell, and Colin Allen. Moral Machines: Teaching Robots Right from Wrong. Oxford: Oxford University Press, 2009.

Wu, Ya-Huei, Christine Fassert, and Anne-Sophie Rigaud. "Designing Robots for the Elderly: Appearance Issue and Beyond.” Archives of Gerontology and Geriatrics 54, no. 1 (January 2012): 121-26. https://doi.org/10.1016/j.archger.2011.02.003.

Wynsberghe, Aimee van. "Designing Robots for Care: Care Centered Value-Sensitive Design.” Science and Engineering Ethics 19, no. 2 (January 3, 2012): 407-33. https://doi.org/10.1007/ s11948-011-9343-6. 